Supporting Information

\title{
STED Nanoscopy Imaging of Cellular Lipid Droplets Employing a Superior Organic Fluorescent Probe
}

Guannan Liu, ${ }^{\dagger}$ Guishan Peng, ${ }^{\dagger}$ Jianan Dai, ${ }^{\dagger}$ Ri Zhou, ${ }^{\dagger}$ Chenguang Wang, ${ }^{\dagger}, *$ Xu Yan, ${ }^{\dagger}$ Xiaoteng Jia, ${ }^{\dagger}$ Xiaomin Liu, ${ }^{\dagger}$ Yuan Gao, ${ }^{\dagger}, *$ Lijun Wang, ${ }^{\dagger,}$ and Geyu $\mathrm{Lu}^{\dagger}$

${ }^{\dagger}$ State Key Laboratory of Integrated Optoelectronics, Key Laboratory of Advanced Gas Sensors of Jilin Province, College of Electronic Science \& Engineering, Jilin University, Changchun 130012, People's Republic of China

* State Key Laboratory of Luminescence and Applications, Changchun Institute of Optics, Fine Mechanics and Physics, Chinese Academy of Sciences, Changchun 130033, People's Republic of China

E-mail: wangchenguang@jlu.edu.cn (C. Wang); gaoyuan@jlu.edu.cn (Y. Gao)

\section{Contents}

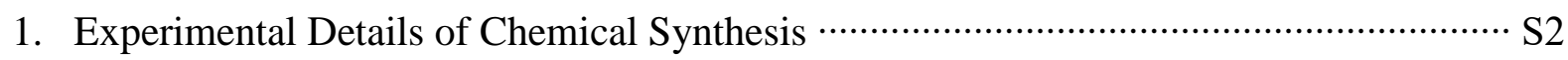

2. Experimental Details of X-ray Crystallographic Analysis …………….................... S3

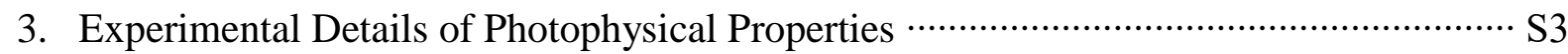

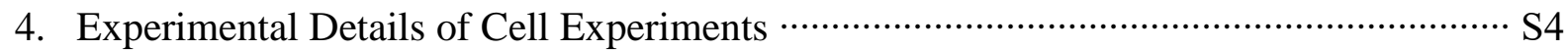

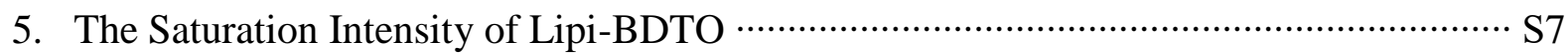

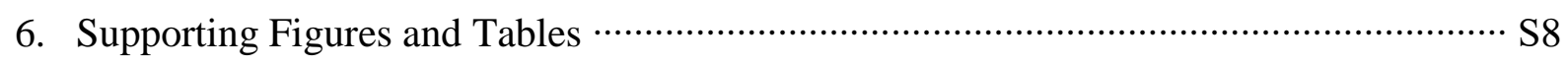

7. NMR and MS Spectra of Synthesized Molecules ……..................................... S18 


\section{Experimental Details of Chemical Synthesis}

General. ${ }^{1} \mathrm{H}$ NMR spectra were recorded with a Zhongke-Niujin AS 400 spectrometer in $\mathrm{CDCl}_{3}$. The chemical shifts in ${ }^{1} \mathrm{H}$ NMR spectra are reported in $\delta$ ppm using tetramethylsilane as an internal standard. The EI-MS spectra were recorded with a Thermo Fisher ITQ1100 spectrometer. All reactions were performed under a $\mathrm{N}_{2}$ atmosphere, unless otherwise stated. Commercially available solvents and reagents were used without further purification unless otherwise mentioned.

Compound 2. The mixture of benzodithiophene dione 1 (4.40 g, $20.0 \mathrm{mmol}$ ), zinc powder $(2.73 \mathrm{~g}, 42 \mathrm{mmol})$ and $\mathrm{NaOH}(12.0 \mathrm{~g}, 30.0 \mathrm{mmol})$ in water $(100 \mathrm{~mL})$ was refluxed for $2 \mathrm{~h}$. Then, 1-bromopropane $(7.38 \mathrm{~g}, 60.0 \mathrm{mmol})$ and a catalytic amount of tetrabutylammonium bromide were added to the reaction. After being refluxed for $12 \mathrm{~h}$, the reaction mixture was poured into water and extracted by $\mathrm{CH}_{2} \mathrm{Cl}_{2}$ for several times. The conbined organic layer was dried over anhydrous $\mathrm{MgSO}_{4}$ and filtraed. After concentration of the filtrate under reduced pressure, the

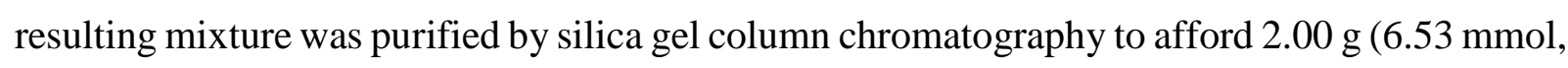
$33 \%$ ) of compound 2 as a white solid. ${ }^{1} \mathrm{H} \mathrm{NMR}\left(400 \mathrm{MHz}, \mathrm{CDCl}_{3}\right): \delta 7.48(\mathrm{~d}, J=5.5 \mathrm{~Hz}, 2 \mathrm{H})$, $7.36(\mathrm{~d}, J=5.5 \mathrm{~Hz}, 2 \mathrm{H}), 4.24(\mathrm{t}, J=5.3 \mathrm{~Hz}, 4 \mathrm{H}), 1.96-1.83(\mathrm{~m}, 4 \mathrm{H}), 1.13(\mathrm{t}, J=7.4 \mathrm{~Hz}, 6 \mathrm{H})$. EI-MS: $m / z$ calcd. for $\mathrm{C}_{16} \mathrm{H}_{17} \mathrm{O}_{2} \mathrm{~S}_{2}: 305.1\left([M-\mathrm{H}]^{+}\right)$; found. 306.4.

Compound 3. Cooling with ice-water bath, the mixture of bromine $(1.56 \mathrm{~g}, 979 \mathrm{mmol})$ and $\mathrm{CH}_{2} \mathrm{Cl}_{2}(10 \mathrm{~mL})$ was slowly added to the solution of compound $2(1.50 \mathrm{~g}, 4.89 \mathrm{mmol})$ in $\mathrm{CH}_{2} \mathrm{Cl}_{2}(20 \mathrm{~mL})$ within $30 \mathrm{~min}$. Then the mixture was stirred for $12 \mathrm{~h}$ at ambient temperature. After removing solvent under reduced pressure, the resulting mixture was purified by silica gel column chromatography to afford $1.71 \mathrm{~g}$ (3.68 mmol, 75\%) of compound $\mathbf{3}$ as a white solid. ${ }^{1} \mathrm{H}$ NMR (400 MHz, $\left.\mathrm{CDCl}_{3}\right): \delta 7.43(\mathrm{~s}, 2 \mathrm{H}), 4.26-4.03(\mathrm{~m}, 4 \mathrm{H}), 1.92-1.79(\mathrm{~m}, 4 \mathrm{H}), 1.11(\mathrm{t}, J=$ $7.4 \mathrm{~Hz}, 6 \mathrm{H})$. EI-MS: $m / z$ calcd. for $\mathrm{C}_{16} \mathrm{H}_{15} \mathrm{Br}_{2} \mathrm{O}_{2} \mathrm{~S}_{2}: 462.9\left([M-\mathrm{H}]^{+}\right)$; found. 464.5 .

Compound 4. To a solution of compound $3(1.00 \mathrm{~g}, 2.15 \mathrm{mmol})$ in $\mathrm{CH}_{2} \mathrm{Cl}_{2}(20 \mathrm{~mL})$ was slowly added $m$-CPBA $(2.62 \mathrm{~g}, 85 \%, 12.9 \mathrm{mmol})$ within $30 \mathrm{~min}$. Then the mixture was refluxed for $48 \mathrm{~h}$. After quenching with the saturated aqueous solution of $\mathrm{NaHCO}_{3}(10 \mathrm{~mL})$, the organic layer was washed with $\mathrm{NaHCO}_{3}$ aqueous solution, and then dried over anhydrous $\mathrm{MgSO}_{4}$, and filtered. After concentration of the filtrate under reduced pressure, the resulting mixture was purified by silica gel column chromatography to afford $0.308 \mathrm{~g}(0.583 \mathrm{mmol}, 27 \%)$ of compound 4 as a yellow solid. ${ }^{1} \mathrm{H}$ NMR (400 MHz, $\left.\mathrm{CDCl}_{3}\right): \delta 7.41(\mathrm{~s}, 2 \mathrm{H}), 4.39(\mathrm{t}, J=6.4 \mathrm{~Hz}$, $4 \mathrm{H}), 1.97-1.84(\mathrm{~m}, 4 \mathrm{H}), 1.10(\mathrm{t}, J=7.4 \mathrm{~Hz}, 6 \mathrm{H})$. EI-MS: $m / z$ calcd. for $\mathrm{C}_{16} \mathrm{H}_{15} \mathrm{Br}_{2} \mathrm{O}_{6} \mathrm{~S}_{2}: 526.9$ $\left([M-\mathrm{H}]^{+}\right)$; found. 524.4. 
Lipi-BDTO. To a mixture of compound $4 \quad(0.200 \quad \mathrm{~g}, \quad 0.379$ mmol), (4methoxyphenyl)boronic acid $(0.230 \mathrm{~g}, 1.51 \mathrm{mmol}), \mathrm{Pd}\left(\mathrm{PPh}_{3}\right)_{4}(0.058 \mathrm{~g}, 0.050 \mathrm{mmol})$ and $\mathrm{K}_{2} \mathrm{CO}_{3}$ (553 mg, $4.00 \mathrm{mmol}$ ) was added the degassed solvent mixture of toluene, ethanol and water $(\mathrm{V} / \mathrm{V} / \mathrm{V}=8: 1: 1,50 \mathrm{~mL})$. Then the reaction mixture was refluxed for $12 \mathrm{~h}$. After cooling to room temperature, the mixture was filtered to remove inorganic salts. The filtate was poured into water and extracted three times with $\mathrm{CH}_{2} \mathrm{Cl}_{2}$. The combined organic layer was washed with brine, and then dried over anhydrous $\mathrm{MgSO}_{4}$, and filtered. After concentration of the filtrate under reduced pressure, the resulting mixture was purified by silica gel column chromatography to afford $0.150 \mathrm{~g}(0.257 \mathrm{mmol}, 68 \%)$ of Lipi-BDTO as a yellow solid. ${ }^{1} \mathrm{H}$ NMR (400 MHz, $\left.\mathrm{CDCl}_{3}\right): \delta 7.78(\mathrm{~d}, J=8.7 \mathrm{~Hz}, 4 \mathrm{H}), 7.29(\mathrm{~s}, 2 \mathrm{H}), 7.00(\mathrm{~d}, J=8.8 \mathrm{~Hz}, 4 \mathrm{H}), 4.45(\mathrm{t}, J=6.5 \mathrm{~Hz}$ $4 \mathrm{H}), 3.87(\mathrm{~s}, 6 \mathrm{H}), 2.01-1.90(\mathrm{~m}, 4 \mathrm{H}), 1.14(\mathrm{t}, J=7.4 \mathrm{~Hz}, 6 \mathrm{H})$. EI-MS: $m / z$ calcd. for $\mathrm{C}_{30} \mathrm{H}_{29} \mathrm{O}_{8} \mathrm{~S}_{2}$ : $581.1\left([M-\mathrm{H}]^{+}\right)$; found. 582.8. The molecular structure has been further determined by single crystal X-ray diffraction analysis (vide infra).

\section{Experimental Details of X-ray Crystallographic Analysis}

Single crystal X-ray measurements. Single crystal X-ray diffraction data were collected on a Rigaku RAXIS-PRID diffractometer using the $\omega$-scan mode with graphite monochromator $\mathrm{Mo} \bullet \mathrm{K} \alpha$ radiation. The structures were solved with direct methods using the SHELXTL programs and refined with full-matrix least-squares on $F^{2}$. Non-hydrogen atoms were refined anisotropically. The positions of hydrogen atoms were calculated and refined isotropically. The crystals of fluorecent probe Lipi-BDTO were obtained by slow evaporation of the solution with mixture solvents of $\mathrm{CH}_{2} \mathrm{Cl}_{2}$ and petroleum ether at room temperature. The crystal structure has been deposited with the Cambridge Crystallographic Data Centre (CCDC: 2083896).

\section{Experimental Details of Photophysical Properties}

Measurements. UV-vis absorption spectra of solutions were measured with a Shimadzu UV-2550 spectrometer. Emission spectra of solutions were measured with an Ocean QE Pro fibre optic spectrometer. Absolute fluorescence quantum yields $\left(\Phi_{\mathrm{F}}\right)$ of solutions were determined with an Ocean QE Pro fibre optic spectrometer equipped with a calibrated integrating sphere system. Fluorescence lifetimes of solutions were measured using an Edinburgh FLS920 spectrometer equipped with a $365 \mathrm{~nm}$ LED excitation source. The fluorescence decay profiles of solutions were fitted reasonably well with a single exponential function. 


\section{Experimental Details of Cell Experiments}

Cell culture. In general, HeLa and HepG2 cells were cultured in Dulbecco's modified Eagle's medium (DMEM, high glucose, pyruvate) containing 10\% fetal bovine serum (FBS) and $1 \%$ Antibiotic-Antimycotic (AA) at $37{ }^{\circ} \mathrm{C}$ in a humidified $5 \%(\mathrm{vol} / \mathrm{vol}) \mathrm{CO}_{2}$ incubator.

Cell viability assays. The effect of probe Lipi-BDTO on cell viability was analyzed using 3-(4,5-dimethylthiazol-2-yl)-2,5-diphenyltetrazolium bromide (MTT). HeLa cells were seeded into a flat-bottomed 96 -well plate $\left(1 \times 10^{4}\right.$ cells/well $)$ and incubated in DMEM containing $10 \%$ FBS (DMEM+) at $37{ }^{\circ} \mathrm{C}$ in a $5 \% \mathrm{CO}_{2} / 95 \%$ air incubator for $24 \mathrm{~h}$. The medium was then replaced with a culture medium DMEM+ containing various concentrations of Lipi-BDTO (0, 0.5, 1.0, 2.0, 5.0 and $10.0 \mu \mathrm{M}$ ) and 1\% DMSO. After incubation for $24 \mathrm{~h}$, MTT reagent (final concentration, $0.5 \mathrm{mg} / \mathrm{mL}$ ) was added to each well, and the plates were incubated for another 4 $\mathrm{h}$ in a $\mathrm{CO}_{2}$ incubator. Excess MTT tetrazolium solution was then removed. After the formazan crystals were solubilized in DMSO $(100 \mu \mathrm{L} /$ well $)$ for $30 \mathrm{~min}$ at room temperature, the absorbance of each well was measured by a microplate reader (Bio-Tek Instruments, Inc) with an excitation at $490 \mathrm{~nm}$.

Co-staining experiments. HeLa or HepG2 cells $\left(5 \times 10^{4}\right)$ were seeded in glass-bottom dishes two days before imaging. After removal of the medium, the cells were stained in DMEM+ containing probes (500 nM Lipi-BDTO and $2 \mu \mathrm{M}$ Ph-Red) and 1\% DMSO for $2 \mathrm{~h}$ in a $\mathrm{CO}_{2}$ incubator. After washing with fresh medium to remove the free probes, the cells were kept in HBSS for imaging. The confocal images were recorded using a Leica TCS SP8 microscope with following set: $\lambda_{\mathrm{ex}}=488 \mathrm{~nm}, \lambda_{\mathrm{em}}=500-530 \mathrm{~nm}$ for Lipi-BDTO; $\lambda_{\mathrm{ex}}=488 \mathrm{~nm}$, $\lambda_{\mathrm{em}}=730-760 \mathrm{~nm}$ for Rh-Red.

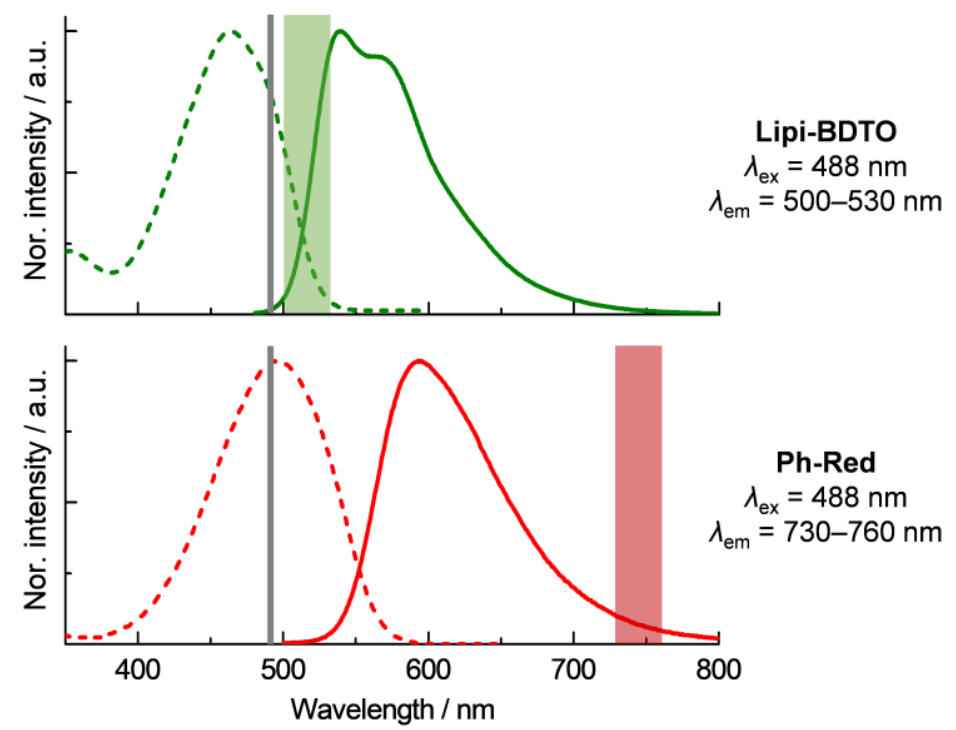

Figure S1. The excitation wavelength (gary line) and the detection range of emission (colored orthogon) of the fluorescent probes used in the co-staining experiments. 
General staining procedure of fluorescent probes. Live HeLa cells were stained in DMEM+ containing fluorescent probe (Lipi-BDTO or Nile Red) and 1\% DMSO for $2 \mathrm{~h}$ in a $\mathrm{CO}_{2}$ incubator. The probe concentration is $2 \mu \mathrm{M}$ unless otherwise mentioned. Then, the cells were washed three times with fresh medium to remove the free probes, and kept in HBSS for confocal imaging and STED imaging.

Confocal imaging. For the comparison of LDs staining specificity of fluorescent probes, the confocal images were recorded using a Nikon A1RMP microscope with following set: $\lambda_{\mathrm{ex}}$ $=488 \mathrm{~nm}, \lambda_{\mathrm{em}}=500-700 \mathrm{~nm}$. For the comparison of the photostability of fluorescent probes, the confocal images were recorded using a Nikon A1RMP microscope with an identical power of excitation laser $(488 \mathrm{~nm})$. The total signal intensities of each image were measured with ImageJ, normalized to the value of the first image and plotted as a function of the number of recorded confocal images.

3D confocal imaging. Live HeLa cells were stained with $2 \mu \mathrm{M}$ Lipi-BDTO for $2 \mathrm{~h}$ and then $20 \mu \mathrm{M}$ Hoechst 33342 for $20 \mathrm{~min}$. After fixing with 4\% paraformaldehyde for $15 \mathrm{~min}$ at room temperature, the cells were kept in PBS for imaging. The Z-stack confocal images were recorded using a Leica TCS SP8 microscope with following set: $\lambda_{\mathrm{ex}}=405 \mathrm{~nm}, \lambda_{\mathrm{em}}=415-480$ $\mathrm{nm}$ for Hoechst $33342 ; \lambda_{\mathrm{ex}}=488 \mathrm{~nm}, \lambda_{\mathrm{em}}=500-700 \mathrm{~nm}$ for Lipi-BDTO; a pixel resolution of $60 \mathrm{~nm} \times 60 \mathrm{~nm}$, a z-step of $200 \mathrm{~nm}$. The two channels were detected via a line-by-line sequential scanning. The reconstruction of 3D confocal image was obtained by the Leica LAS X software.

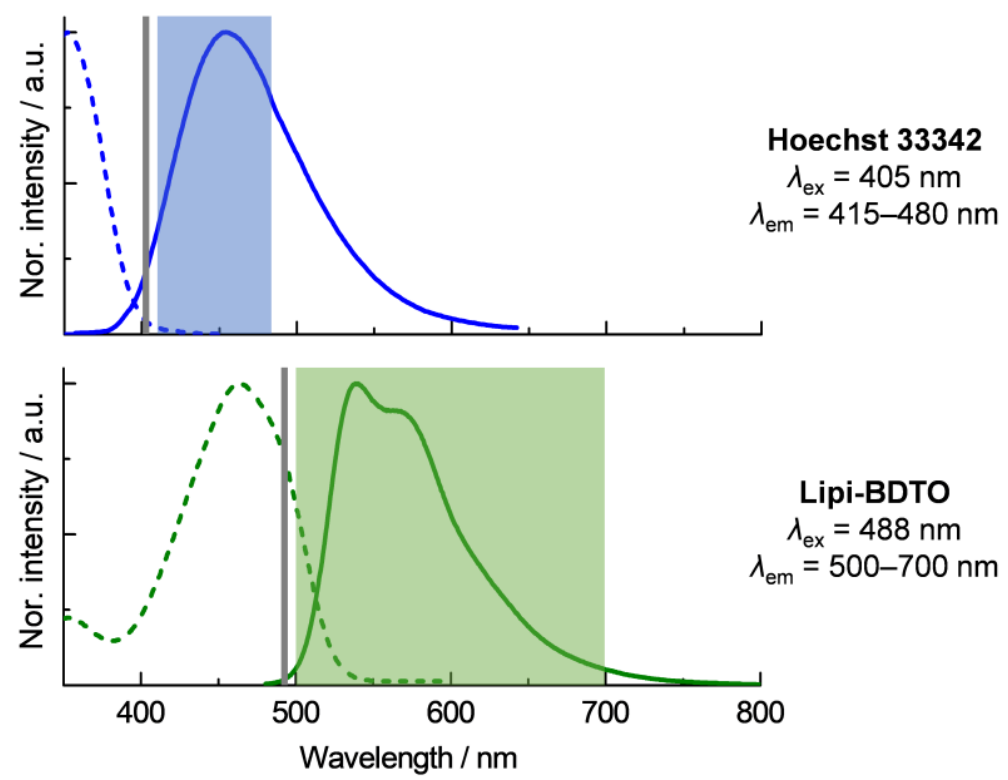

Figure S2. The excitation wavelength (gary line) and the detection range of emission (colored orthogon) of the fluorescent probes used in the 3D confocal imaging experiments. 
Multicolor confocal imaging. Live HeLa cells were stained in DMEM+ containing $2 \mu \mathrm{M}$ Lipi-BDTO and $1 \%$ DMSO for $2 \mathrm{~h}$ in a $\mathrm{CO}_{2}$ incubator. After washing with fresh medium, the cells were then stained in DMEM+ containing $50 \mathrm{nM}$ MitoTracker Deep Red FM, $20 \mu \mathrm{M}$ Hoechst 33342 and $0.5 \%$ DMSO for $20 \mathrm{~min}$ in a $\mathrm{CO}_{2}$ incubator. After washing with fresh medium again, the cells were further stained in DMEM+ containing $50 \mathrm{nM}$ LysoTracker Red and $1 \%$ DMSO for 20 min in a $\mathrm{CO}_{2}$ incubator. Without washing, the cells were imaged by a Leica TCS SP8 microscope with following set: $\lambda_{\mathrm{ex}}=405 \mathrm{~nm}, \lambda_{\mathrm{em}}=415-450 \mathrm{~nm}$ for Hoechst $33342 ; \lambda_{\mathrm{ex}}=488 \mathrm{~nm}, \lambda_{\mathrm{em}}=500-550 \mathrm{~nm}$ for Lipi-BDTO; $\lambda_{\mathrm{ex}}=570 \mathrm{~nm}, \lambda_{\mathrm{em}}=580-620 \mathrm{~nm}$ for LysoTracker Red; $\lambda_{\mathrm{ex}}=650 \mathrm{~nm}, \lambda_{\mathrm{em}}=660-750 \mathrm{~nm}$ for MitoTracker Deep Red. The four channels were detected via a line-by-line sequential scanning.
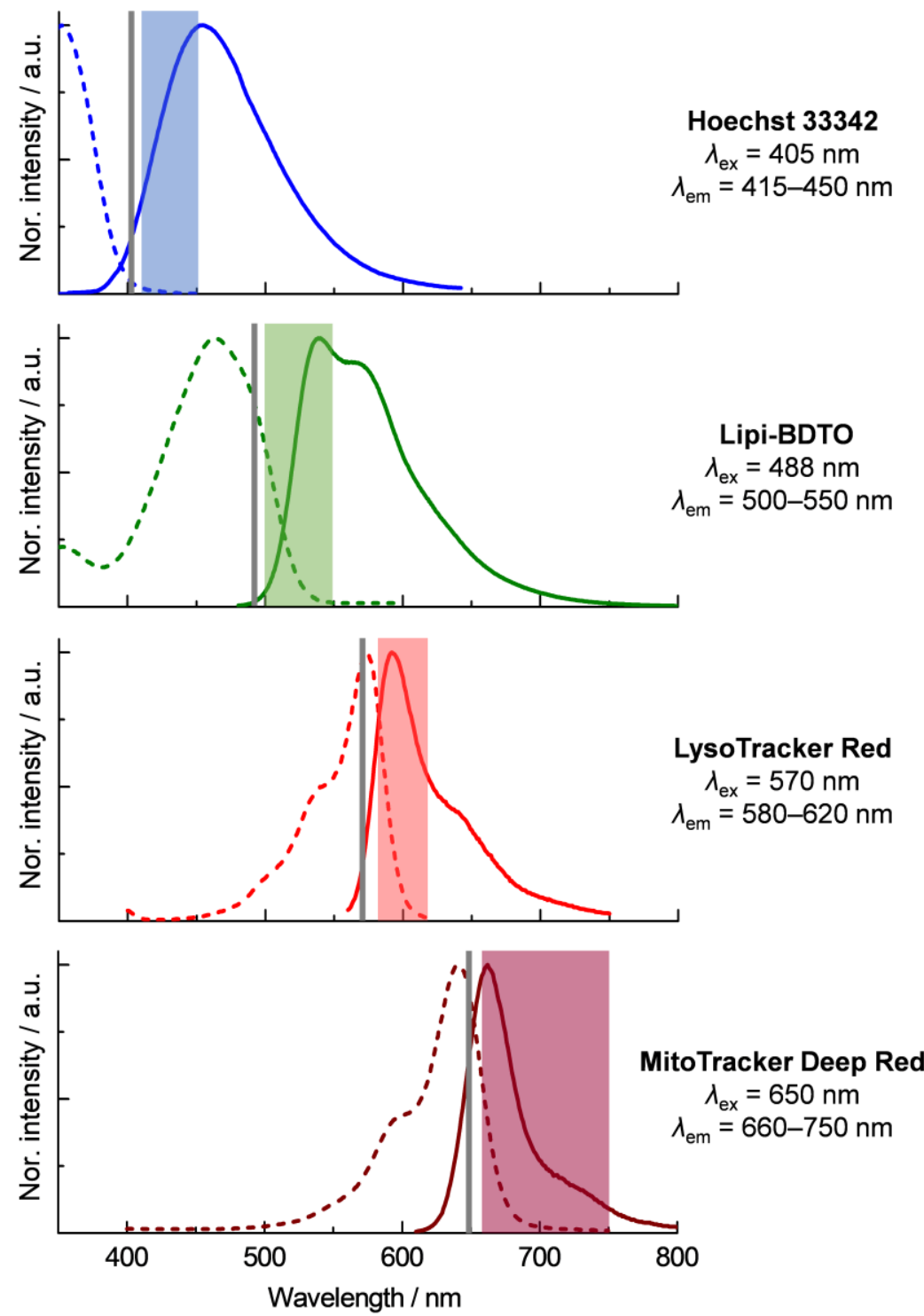

Figure S3. The excitation wavelength (gary line) and the detection range of emission (colored orthogon) of the fluorescent probes used in the multicolor confocal imaging experiments. 


\section{The Saturation Intensity of Lipi-BDTO}

According to the STED imaging theory, the saturation intensity $I_{\text {sat }}$ is determined by the following equation:

$$
I_{\mathrm{sat}}=\frac{h c}{\sigma \tau \lambda_{S T E D}}
$$

where $h$ is the Planck constant, $c$ is the speed of light, $\sigma$ is the cross section at the STED laser wavelength, $\tau$ is the fluorescence lifetime of molecule, $\lambda_{\text {STED }}$ is the wavelength of STED laser. Since the $h, \mathrm{c}$, and $\lambda_{\text {STED }}$ are constants, the before mentioned equation is usually simplified to be:

$$
I_{\mathrm{sat}} \propto \frac{1}{\sigma \tau}
$$

Generally, the $\sigma$ has a direct relationship with the relative emission intensity at the STED laser wavelength, i.e. larger overlap between STED laser and emission spectrum could provide a higher value of $\sigma$.

For fluorescent probe Lipi-BDTO, the large Stokes shift enables with a significant overlap between the $660 \mathrm{~nm}$ STED laser and the emission spectrum, thus resulting a large $\sigma$ and accordingly a small $I_{\text {sat. }}$ 


\section{Supporting Figures and Tables}

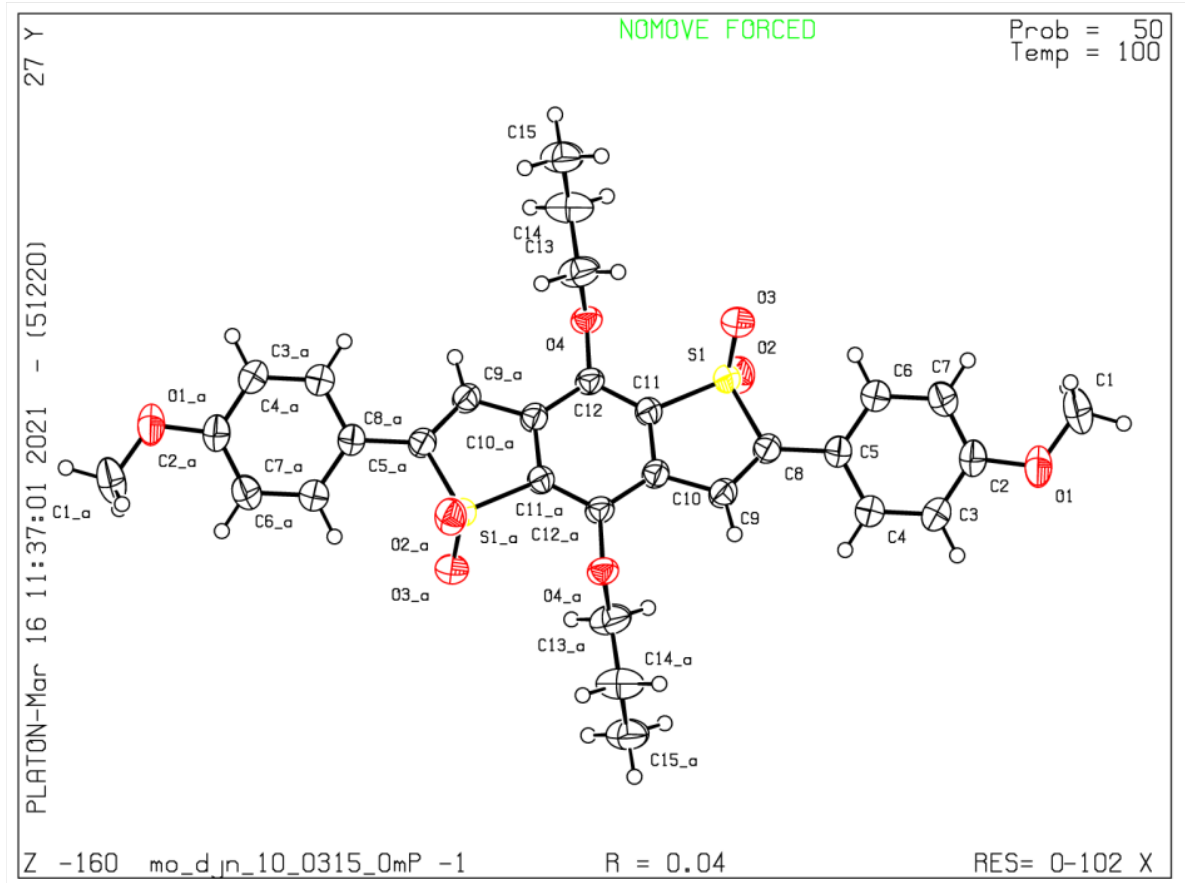

Figure S4. X-ray single-crystal structure of Lipi-BDTO (CCDC: 2083896).

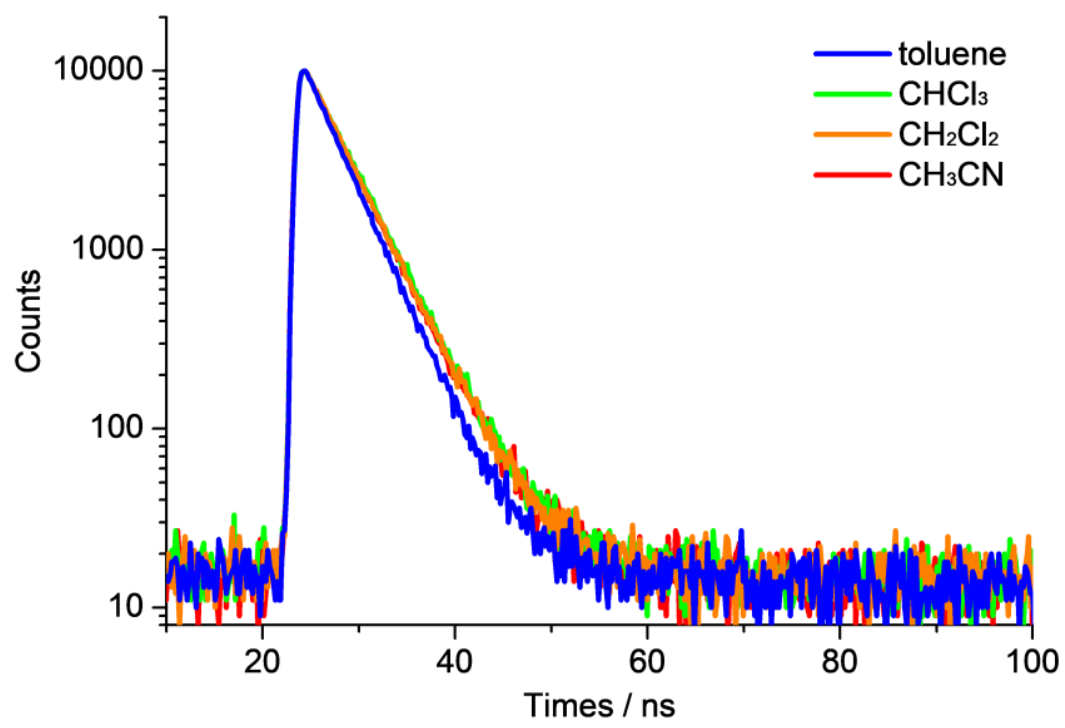

Figure S5. The fluorescence decay profiles of Lipi-BDTO in various organic solvents. 


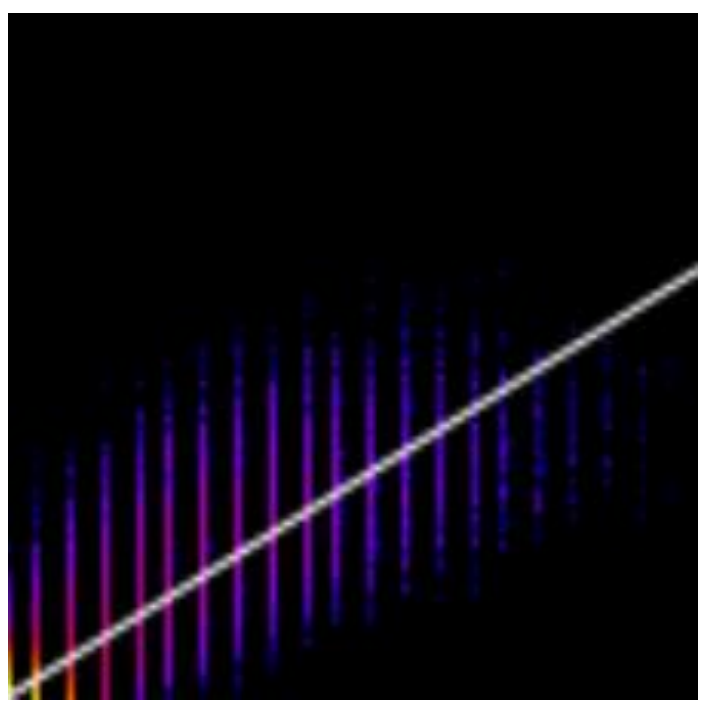

Figure S6. Pearson's correlation coefficient $(R=0.85)$ plot of two channels of co-localization confocal imaging.
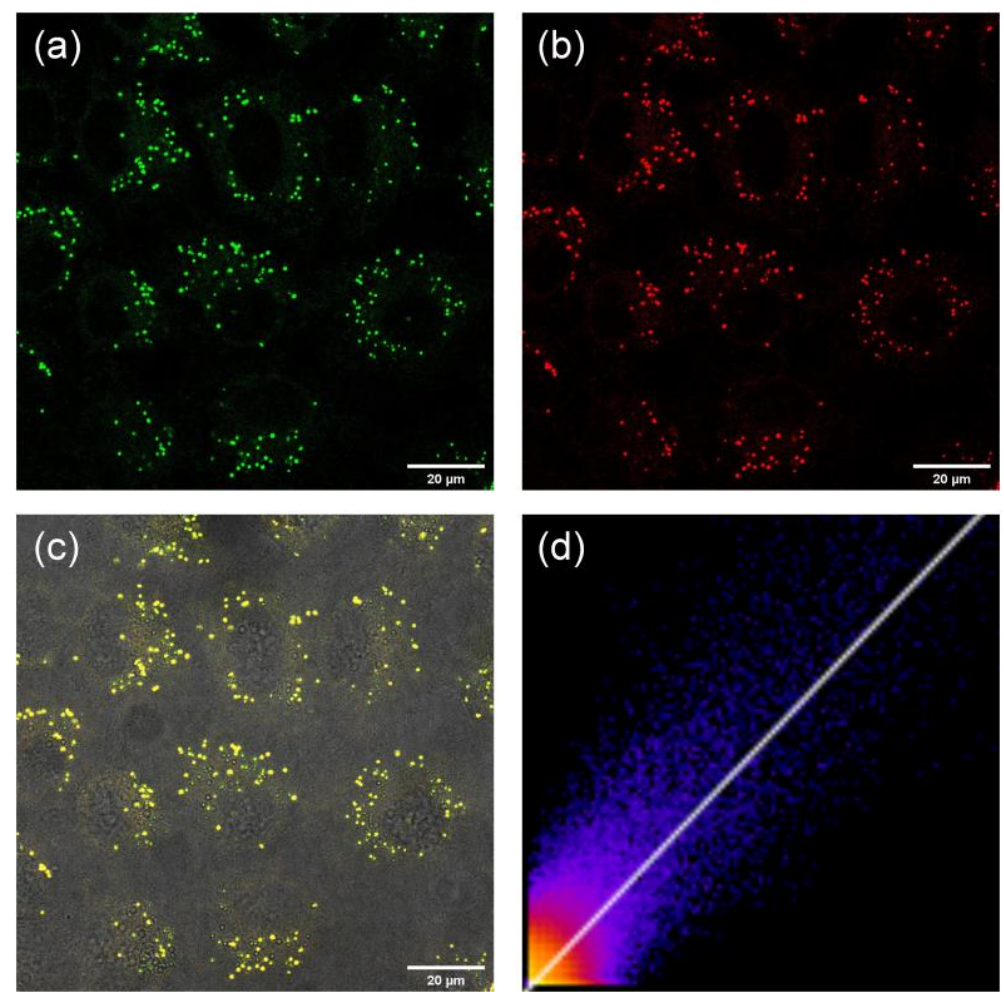

Figure S7. Confocal images of HepG2 cells simultaneously labeled with Lipi-BDTO and PhRed: a) Lipi-BDTO; b) Ph-Red; c) merge image of a) and b) and bright filed; d) Pearson's correlation coefficient $(R=0.86)$ plot of a) and b); scale bar: $20 \mu \mathrm{m}$. 

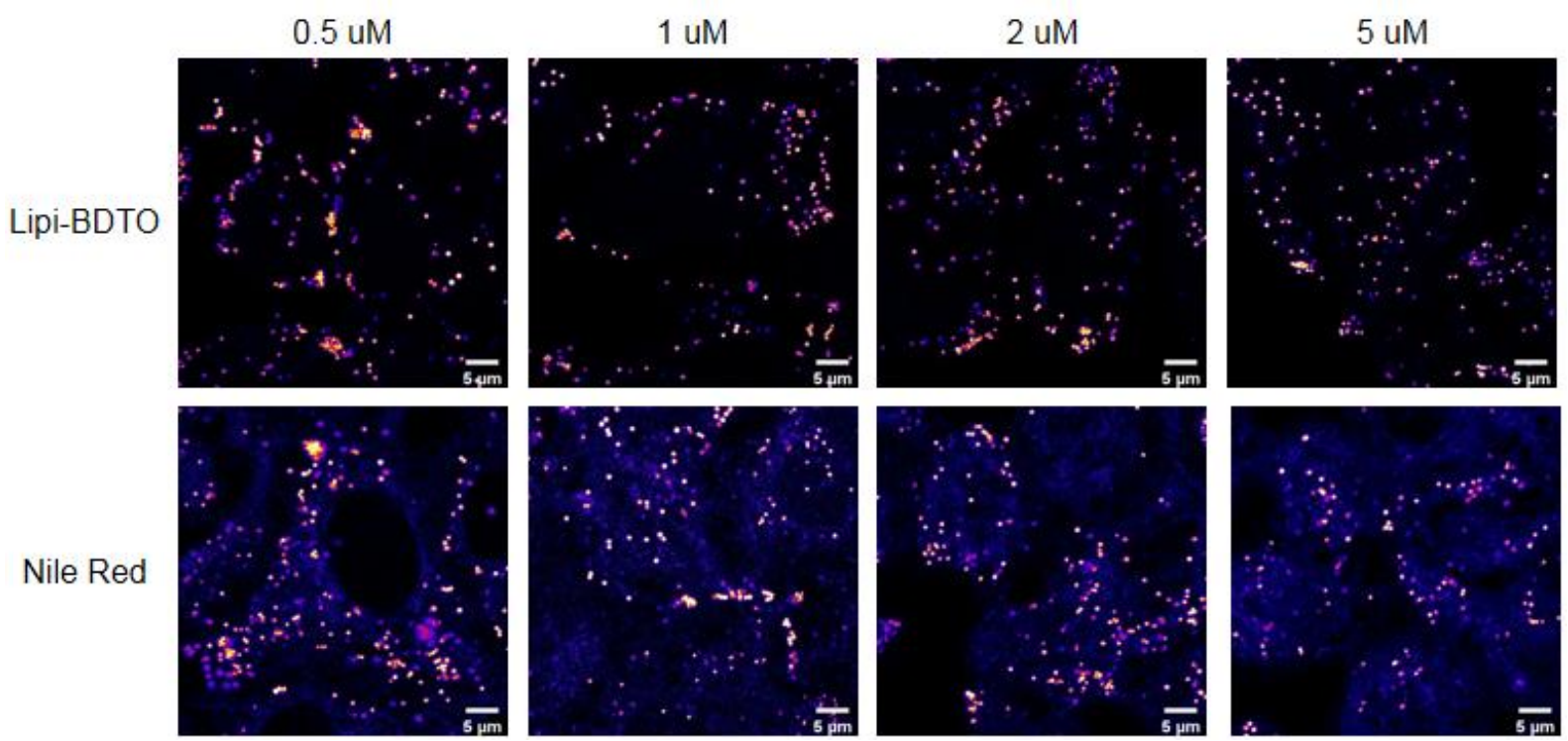

Figure S8. Comparison of the cellular staining specificity towards LDs between Lipi-BDTO and Nile Red at various concentrations (2 h). Scale bar: $5 \mu \mathrm{m}$. 


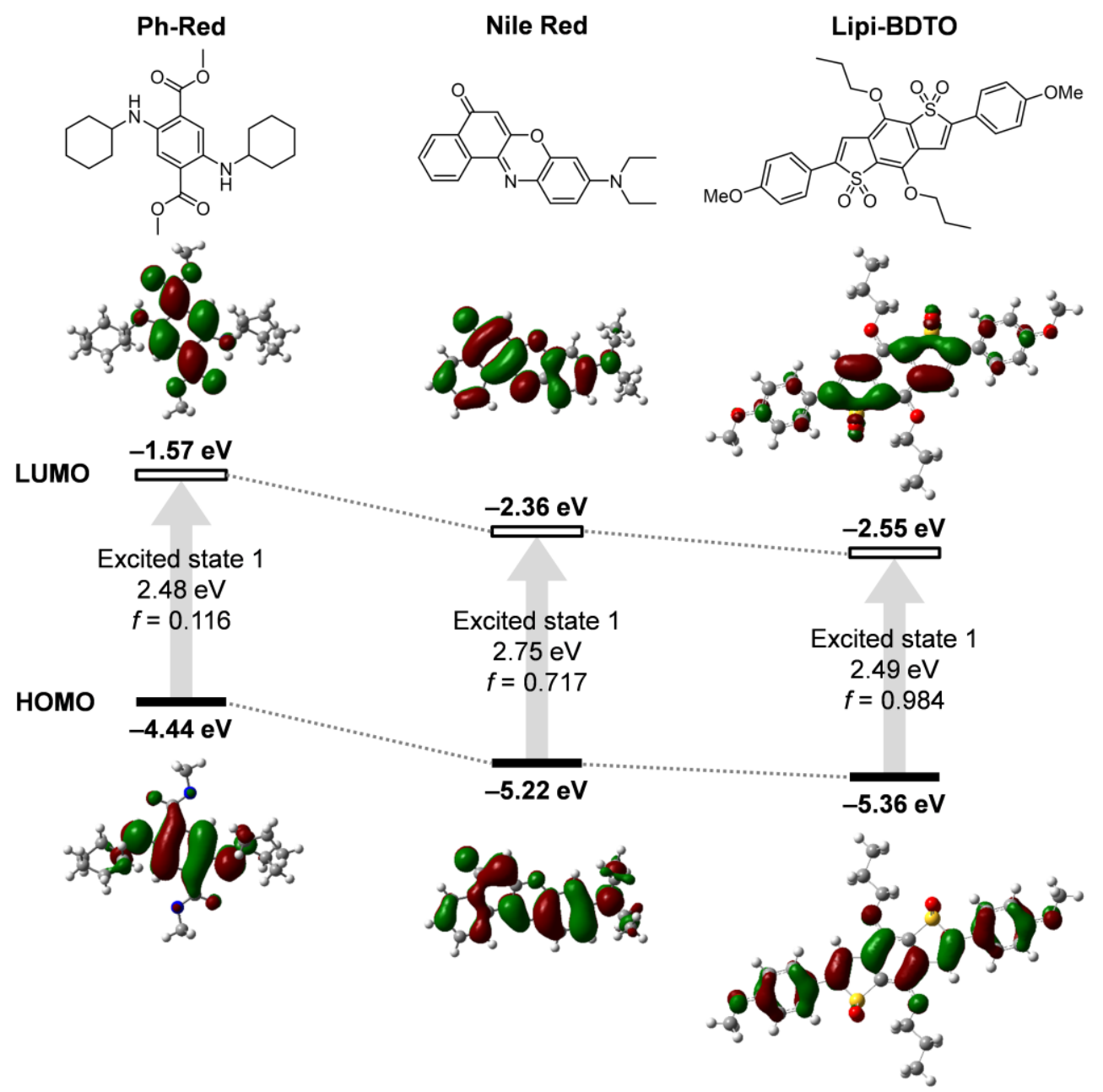

Figure S9. TD-DFT calculation (B3LYP/6-31G*, Gaussian 16) results of the lipid droplets fluorescent probes Ph-Red, Nile Red and Lipi-DBTO: energy diagram, Kohn-Sham HOMO and LUMO, vertical excitation energy, and oscillator strength $(f)$. The first excited state corresponds to the transition of HOMO to LUMO. 
(a)

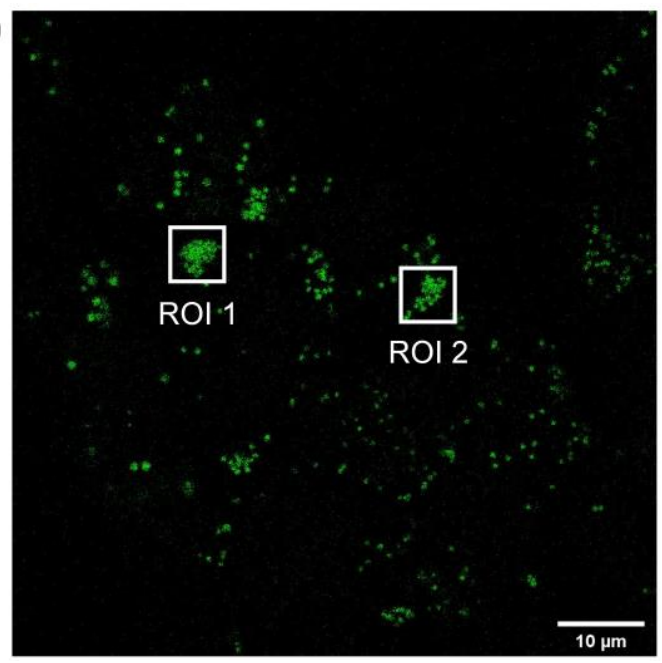

(b)

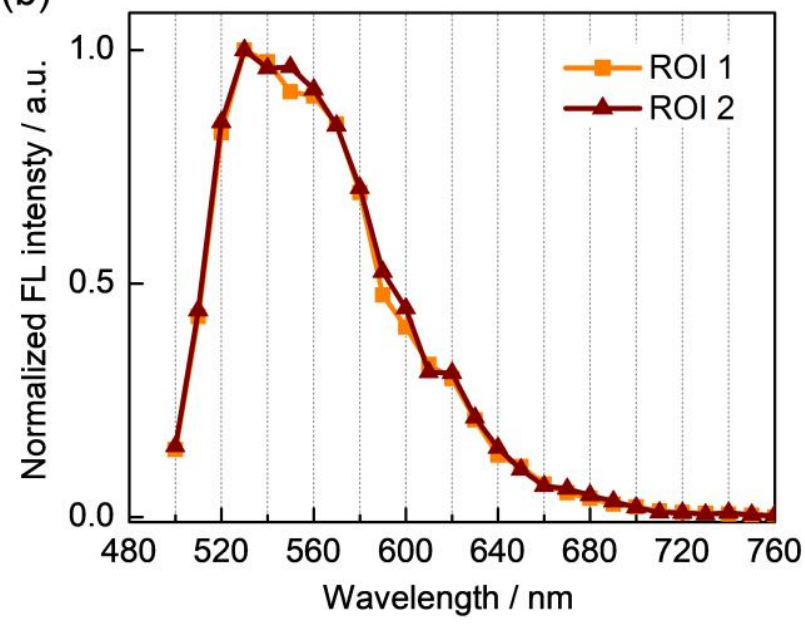

Figure S10. The fluorescence spectra of Lipi-BDTO in living HeLa cells measured by in-situ wavelength scan: a) the confocal image with two different regions of interest (ROI 1 and ROI 2); b) the emission spectra of ROI 1 and ROI 2 with maxima of around $540 \mathrm{~nm}$. Scale bar: 10 $\mu \mathrm{m}$.

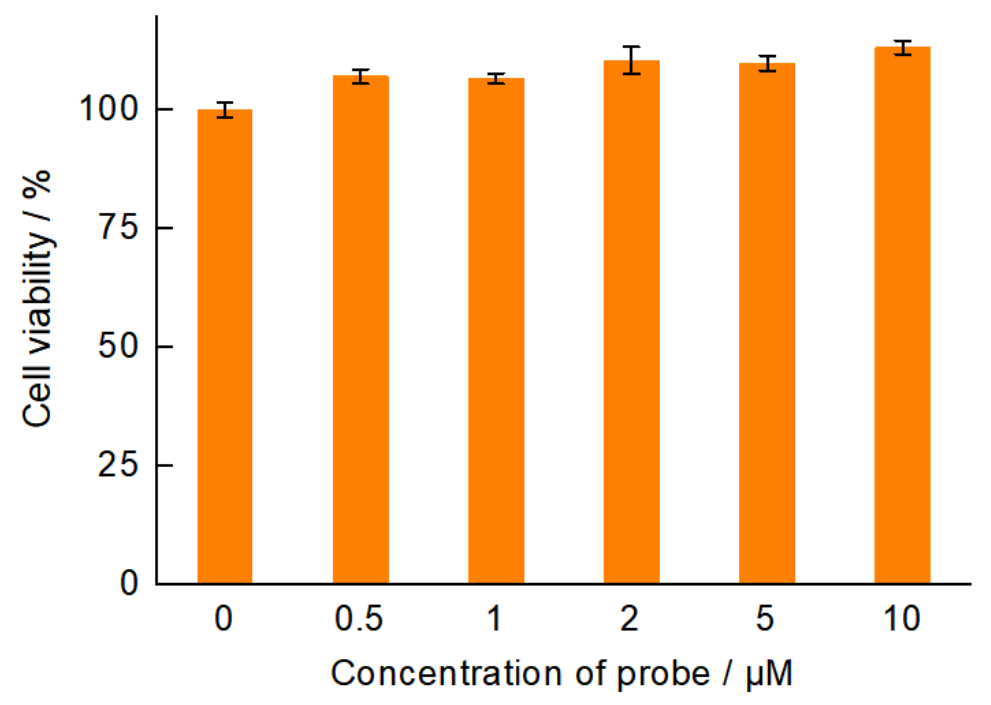

Figure S11. Cell viability results of the HeLa cells stained with Lipi-BDTO by MTT assay. The results are expressed as percentages of the probe-free controls. All data are presented as mean \pm s.d. $(n=10)$. 
(a)

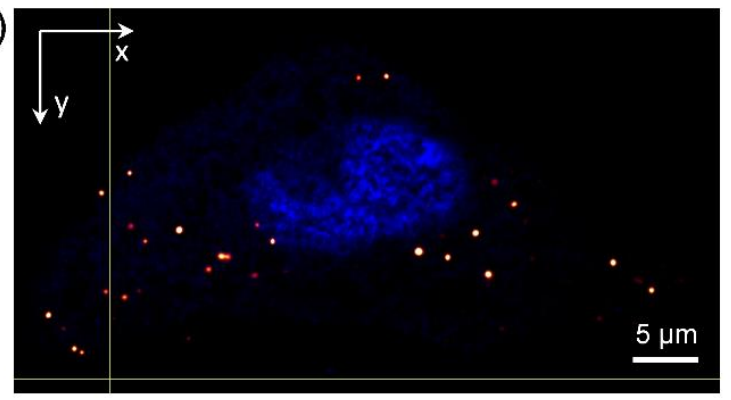

(d)

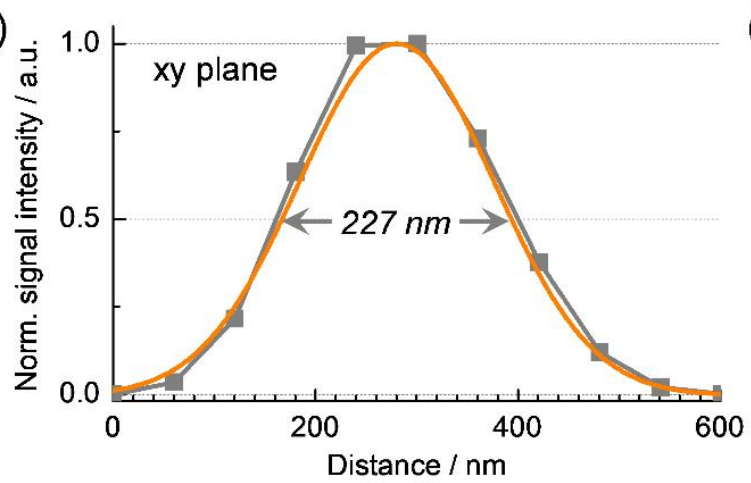

(b)

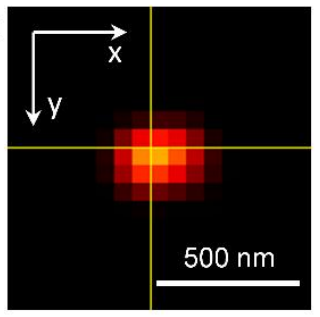

(c)

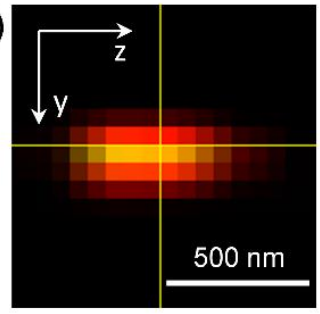

(e)

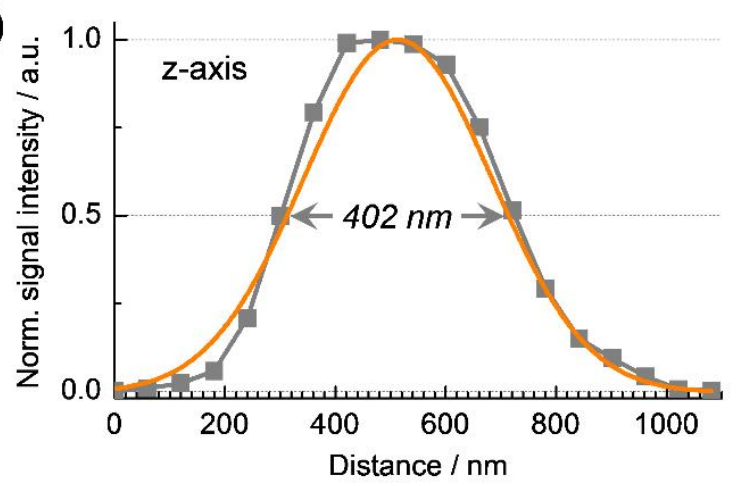

Figure S12. Determination of the resolution of 3D confoal imaging: $(a-c)$ orthogonal view (xy and yz planes) of a small lipid droplet, which is used for determination of the FWHM resolution; (d, e) the signal intensity profiles (gray line) crossed the lipid droplet; the FWHM resolutions of the xy plane and z-axis are calculated from Gaussian fitting (orange line). 

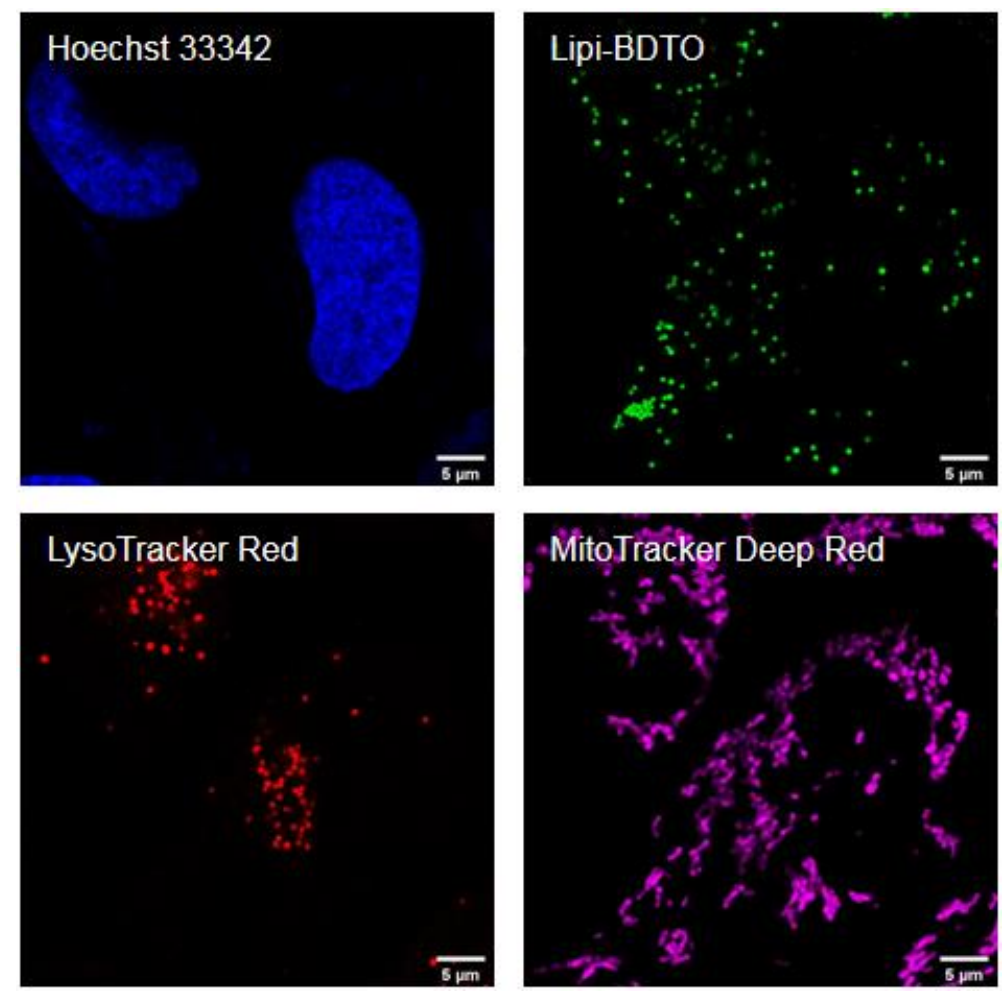

Figure S13. Multicolor confocal imaging of living HeLa cells: four imaging channels of Hoechst 33342, Lipi-BDTO, LysoTracker Red and MitoTracker Deep Red, respectively. Scale bar: $5 \mu \mathrm{m}$. 
Table S1. Comparison of the Nanoscopy Imaging of LDs Reported in the Literatures

\begin{tabular}{|c|c|c|c|c|c|c|}
\hline Year & $\begin{array}{l}\text { Nanoscopy } \\
\text { imaging } \\
\text { technique }\end{array}$ & $\begin{array}{l}\text { Fluorescent } \\
\text { probe }\end{array}$ & $\begin{array}{l}\text { Saturation } \\
\text { intensity } I_{\text {sat }}\end{array}$ & $\begin{array}{l}\text { Resolution of } 2 \mathrm{D} \\
\text { image }\end{array}$ & $\begin{array}{l}\text { Resolution of 3D } \\
\text { image }\end{array}$ & $\begin{array}{l}\text { Refer } \\
\text { ence }\end{array}$ \\
\hline 2018 & SIM & NIM-3A & - & No data & Not used for $3 \mathrm{D}$ & 1 \\
\hline 2019 & SIM & NIM-7 & - & No data & Not used for 3D & 2 \\
\hline 2019 & PALM & SNile Red & - & $<250 \mathrm{~nm}$ & Not used for 3D & 3 \\
\hline 2019 & STED & PyLa-C17Cer & No data & $\sim 300 \mathrm{~nm}$ & Not used for 3D & 4 \\
\hline 2019 & STED & CM2P & No data & $\sim 300 \mathrm{~nm}$ & $\begin{array}{l}\text { Used for } 3 \mathrm{D} \text {, but } \\
\text { no data }\end{array}$ & 5 \\
\hline 2021 & STED & LAQ1 & No data & $166 \mathrm{~nm}$ & Not used for $3 \mathrm{D}$ & 6 \\
\hline 2021 & STED & BoCz-Lip & No data & $<100 \mathrm{~nm}$ & $\begin{array}{l}\text { Used for } 3 \mathrm{D} \text {, but } \\
\text { no data }\end{array}$ & 7 \\
\hline 2021 & STED & DTPA-BT-M & No data & $95 \mathrm{~nm}$ & Not used for 3D & 8 \\
\hline 2021 & STED & Lipi-DSB & $\begin{array}{l}10.1 \\
\mathrm{~cm}^{-2}\end{array} \quad \mathrm{MW}$ & $\begin{array}{l}58 \mathrm{~nm} \\
\left(@ 40 \mathrm{MW} \mathrm{cm}^{-2} \text { ) }\right.\end{array}$ & $\begin{array}{l}8.9 \times 10^{5} \mathrm{~nm}^{3} \\
(\text { xyz: } 77 \times 77 \times \\
\left.150 \mathrm{~nm}^{3}\right)\end{array}$ & 9 \\
\hline $\begin{array}{l}\text { This } \\
\text { work }\end{array}$ & STED & Lipi-BDTO & $\begin{array}{l}6.8 \\
\mathrm{~cm}^{-2}\end{array} \quad \mathrm{MW}$ & $\begin{array}{l}65 \mathrm{~nm} \\
\left(@ 16 \mathrm{MW} \mathrm{cm}^{-2} \text { ) }\right.\end{array}$ & $\begin{array}{l}8.9 \times 10^{5} \mathrm{~nm}^{3} \\
(\text { xyz: } 90 \times 90 \times \\
\left.110 \mathrm{~nm}^{3}\right)\end{array}$ & \\
\hline
\end{tabular}

Referecnces:

[1] X. Zheng, W. Zhu, F. Ni, H. Ai, C. Yang, Sensor. Actuat. B-Chem. 2018, 255, 3148.

[2] X. Zheng, W. Zhu, F. Ni, H. Ai, S. Gong, X. Zhou, J. L. Sessler, C. Yang, Chem. Sci. 2019, 10, 2342.

[3] J. Tang, M. A. Robichaux, K. L. Wu, J. Pei, N. T. Nguyen, Y. Zhou, T. G. Wensel, H. Xiao, J. Am. Chem. Soc. 2019, 141, 14699.

[4] D. O’ Connor, A. Byrne, G. B. Berselli, C. Long, T. E. Keyes, Analyst 2019, 144, 1608.

[5] H. Xu, H. Zhang, G. Liu, L. Kong, X. Zhu, X. Tian, Z. Zhang, R. Zhang, Z. Wu, Y. Tian, H. Zhou, Anal. Chem. 2019, 91, 977.

[6] M. Taki, K. Kajiwara, E. Yamaguchi, Y. Sato, S. Yamaguchi, ACS Materials Lett. 2021, 3, 42.

[7] X. Liu, X. Lu, T. Zhu, D. Wenli, Y. Zhenghui, H. Cao, S. Wang, Y. Tian, Z. Zhang, R. Zhang, S. C. D. Souza, X. Tian, Biosens. Bioelectron. 2021, 175, 112871. 
[8] Y. Xu, H. Zhang, N. Zhang, R. Xu, Z. Wang, Y. Zhou, Q. Shen, D. Dang, L. Meng and B. Z. Tang, Mater. Chem. Front. 2021, 5, 1872.

[9] R. Zhou, C. Wang, X. Liang, F. Liu, X. Yan, X. Liu, P. Sun, H. Zhang, Y. Wang, G. Lu, ACS Materials Lett. 2021, 3, 516.

(a)

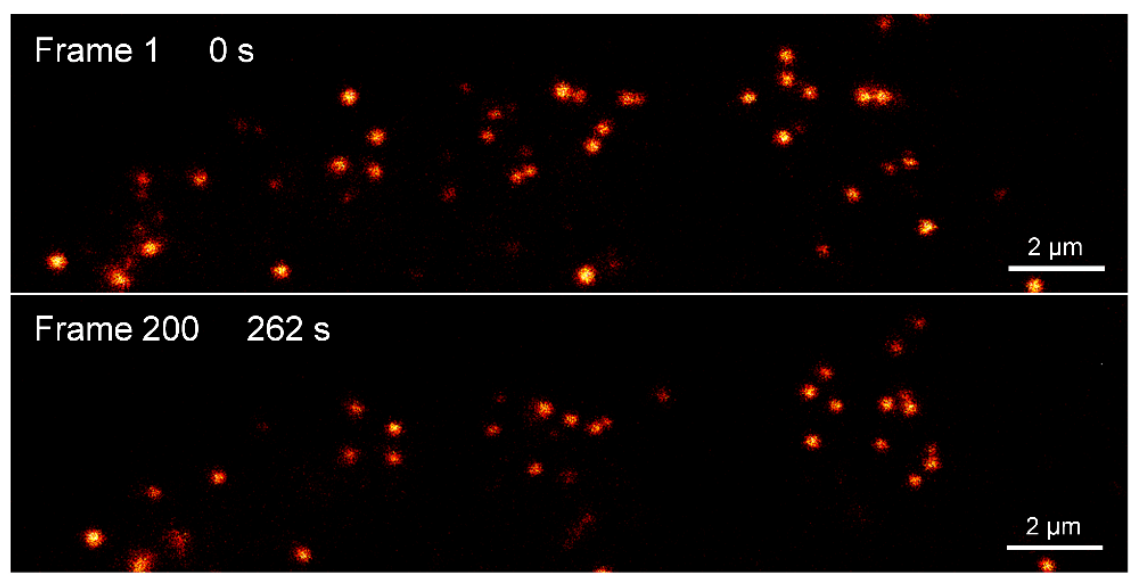

(b)

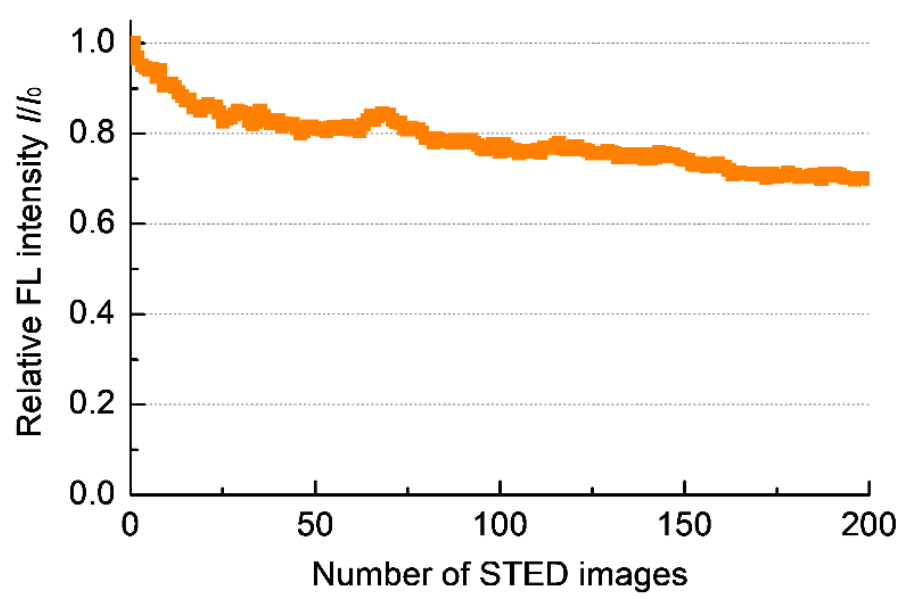

Figure S14. Time-lapse STED nanoscopy imaging of living HeLa cells stained with LipiBDTO: (a) recording 200 STED frames (262 s); (b) the fluorescence intensity of each STED image $(I)$ relative to the initial value $\left(I_{0}\right)$ plotted as a function of the recorded number. 
Table S2. State-of-the-Art Performance of STED Nanoscopy Imaging Employing Various Organic Fluorescent Probes

\begin{tabular}{|c|c|c|c|c|c|c|}
\hline Year & $\begin{array}{l}\text { Fluorescent } \\
\text { probe }\end{array}$ & $\begin{array}{l}\text { Cellular } \\
\text { organelle }\end{array}$ & $\begin{array}{l}\text { Resolution } \\
\text { of } 2 \mathrm{D} \text { image }\end{array}$ & $\begin{array}{l}\text { Time-lapse } \\
\text { nanoscopy } \\
\text { imaging }\end{array}$ & $\begin{array}{l}\text { Resolution } \\
\text { of 3D image }\end{array}$ & $\begin{array}{l}\text { Refere } \\
\text { nce }\end{array}$ \\
\hline 2019 & $\begin{array}{l}\text { Mito-PB } \\
\text { Yellow }\end{array}$ & $\begin{array}{l}\text { Mitochondrial } \\
\text { cristae }\end{array}$ & $58 \mathrm{~nm}$ & 700 frames & $\begin{array}{l}\text { Not used for } \\
\text { 3D }\end{array}$ & 1 \\
\hline 2019 & COX8A-SNAP & $\begin{array}{l}\text { Mitochondrial } \\
\text { cristae }\end{array}$ & $\sim 50 \mathrm{~nm}$ & 16 frames & $\begin{array}{l}\text { Not used for } \\
\text { 3D }\end{array}$ & 2 \\
\hline 2020 & MitoESq-635 & $\begin{array}{l}\text { Mitochondrial } \\
\text { cristae }\end{array}$ & $35.2 \mathrm{~nm}$ & 51 frames & $\begin{array}{l}\text { xy: } 51 \mathrm{~nm} \\
\mathrm{z}: \sim 400 \mathrm{~nm}\end{array}$ & 3 \\
\hline 2014 & SiR-tubulin & Tubulins & $39 \mathrm{~nm}$ & 20 frames & $\begin{array}{l}\text { Not used for } \\
\text { 3D }\end{array}$ & 4 \\
\hline 2017 & PB430-IgG & Tubulins & $76 \mathrm{~nm}$ & 30 frames & $\mathrm{z}: 160 \mathrm{~nm}$ & 5 \\
\hline 2015 & SiR-Hoechst & DNA & $78 \mathrm{~nm}$ & - & $\begin{array}{l}\text { Not used for } \\
\text { 3D }\end{array}$ & 6 \\
\hline 2020 & $\begin{array}{l}\text { Lyso-PB } \\
\text { Yellow }\end{array}$ & $\begin{array}{l}\text { Lysosome } \\
\text { membrane }\end{array}$ & $70 \mathrm{~nm}$ & - & $\begin{array}{l}\text { Not used for } \\
\text { 3D }\end{array}$ & 7 \\
\hline $\begin{array}{l}\text { This } \\
\text { work }\end{array}$ & Lipi-BDTO & Lipid droplets & $65 \mathrm{~nm}$ & 200 frames & $\begin{array}{l}x y: 90 \mathrm{~nm} \\
\mathrm{z}: 110 \mathrm{~nm}\end{array}$ & \\
\hline
\end{tabular}

\section{References:}

[1] C. Wang, M. Taki, Y. Sato, Y. Tamura, H. Yaginuma, Y. Okada, S. Yamaguchi, Proc. Natl. Acad. Sci. USA 2019, 116, 15817.

[2] T. Stephan, A. Roesch, D. Riedel, S. Jakobs, Sci. Rep. 2019, 9, 12419.

[3] X. Yang, Z. Yang, Z. Wu, Y. He, C. Shan, P. Chai, C. Ma, M. Tian, J. Teng, D. Jin, W. Yan, P. Das, J. Qu, P. Xi, Nat. Commun. 2020, 11, 3699.

[4] G. Lukinavičius, L. Reymond, E. D'Este, A. Masharina, F. Göttfert, H. Ta, A. Güther, M. Fournier, S. Rizzo, H. Waldmann, C. Blaukopf, C. Sommer, D. W. Gerlich, H. D. Arndt, S. W. Hell, K. Johnsson, Nat. Methods 2014, 11, 731.

[5] C. Wang, M. Taki, Y. Sato, A. Fukazawa, T. Higashiyama, S. Yamaguchi, J. Am. Chem. Soc. 2017, 139, 10374.

[6] G. Lukinavičius, C. Blaukopf, E. Pershagen, A. Schena, L. Reymond, E. Derivery, M. Gonzalez-Gaitan, E. D'Este, S. W. Hell, D. W. Gerlich, K. Johnsson, Nat. Commun. 2015, 6, 8497.

[7] C. Wang, M. Taki, K. Kajiwara, J. Wang, S. Yamaguchi, ACS Materials Lett. 2020, 2, 705. 
7. NMR and MS Spectra of Synthesized Molecules
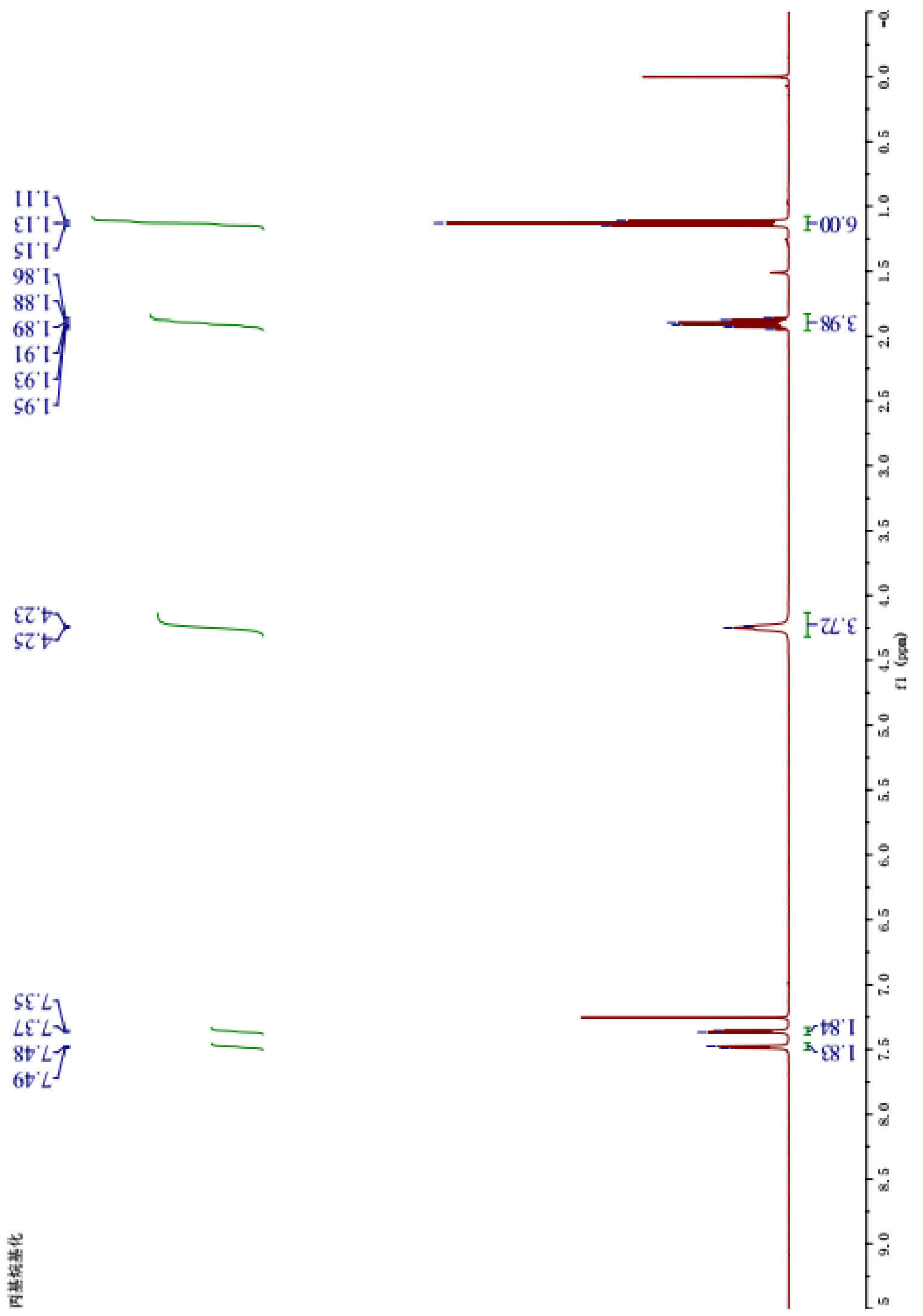

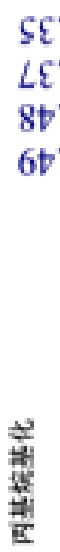

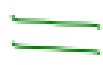

$8 b^{\prime} L \mathcal{L}$

$6 b^{\prime} L$

Figure S15. ${ }^{1} \mathrm{H}$ NMR spectrum of compound $2\left(400 \mathrm{MHz}, \mathrm{CDCl}_{3}\right)$. 

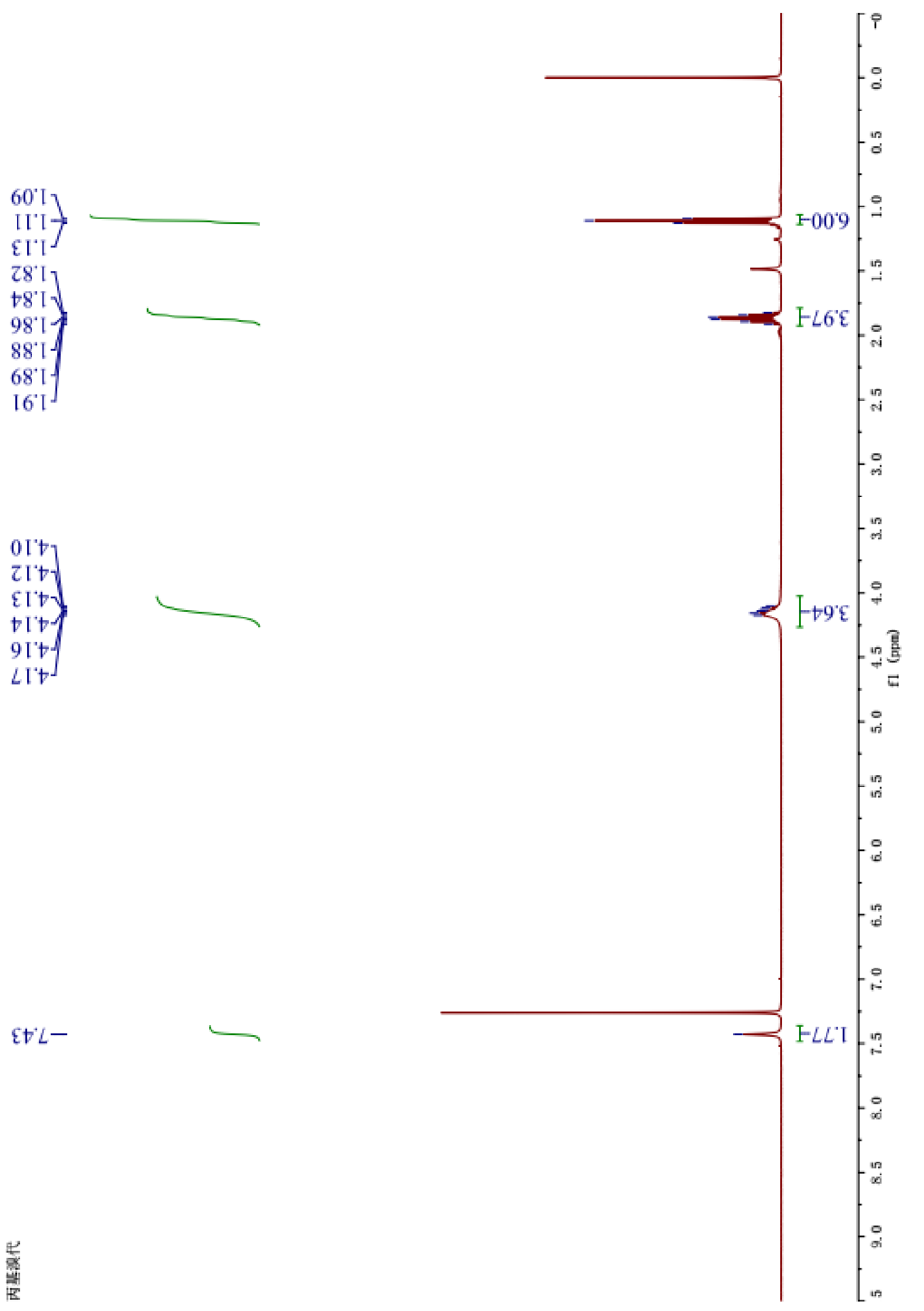

$\varepsilon t L^{\circ}$

墨

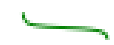

Figure S16. ${ }^{1} \mathrm{H}$ NMR spectrum of compound $3\left(400 \mathrm{MHz}, \mathrm{CDCl}_{3}\right)$. 

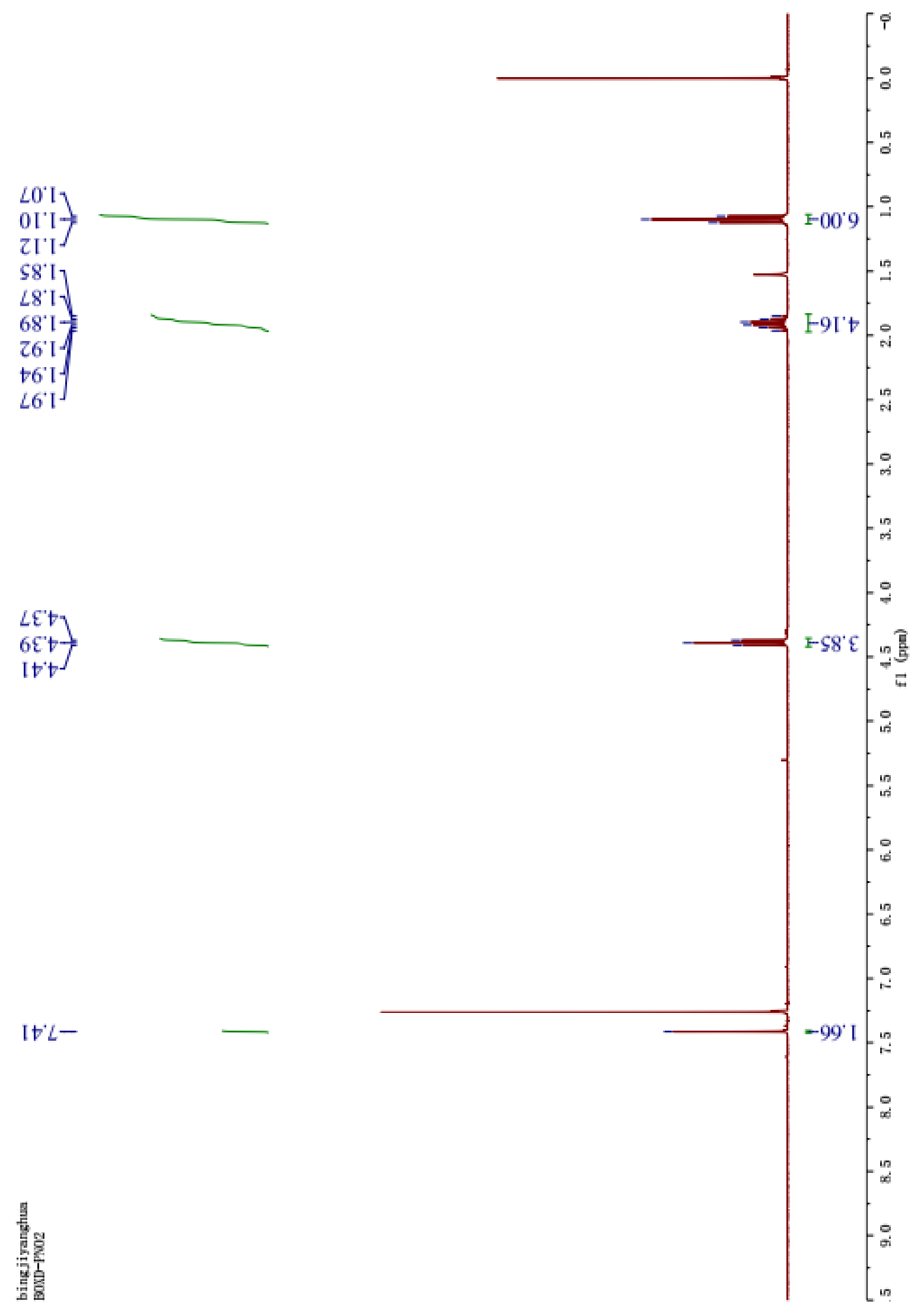


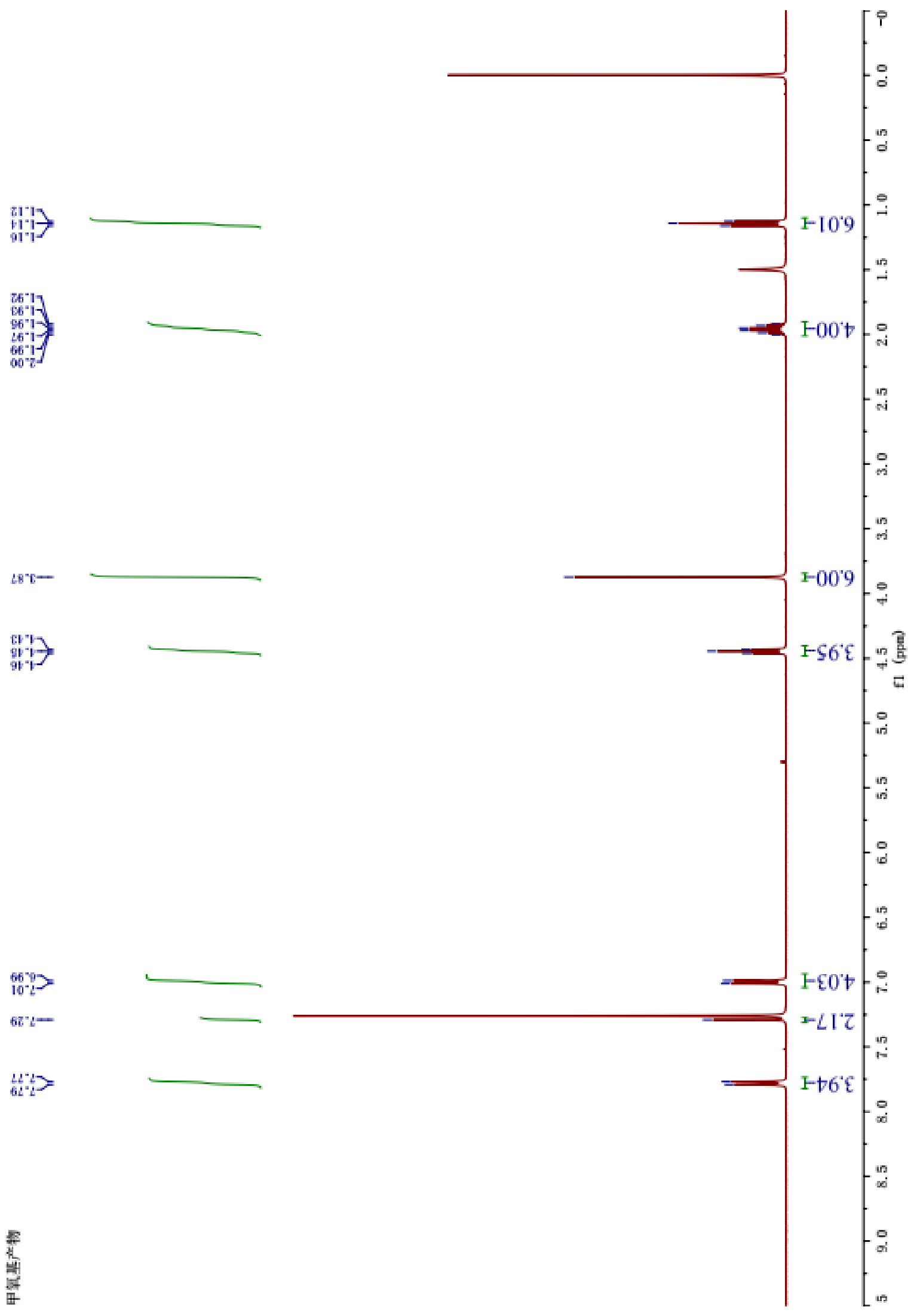

Figure S18. ${ }^{1} \mathrm{H}$ NMR spectrum of probe Lipi-BDTO (400 MHz, $\left.\mathrm{CDCl}_{3}\right)$. 


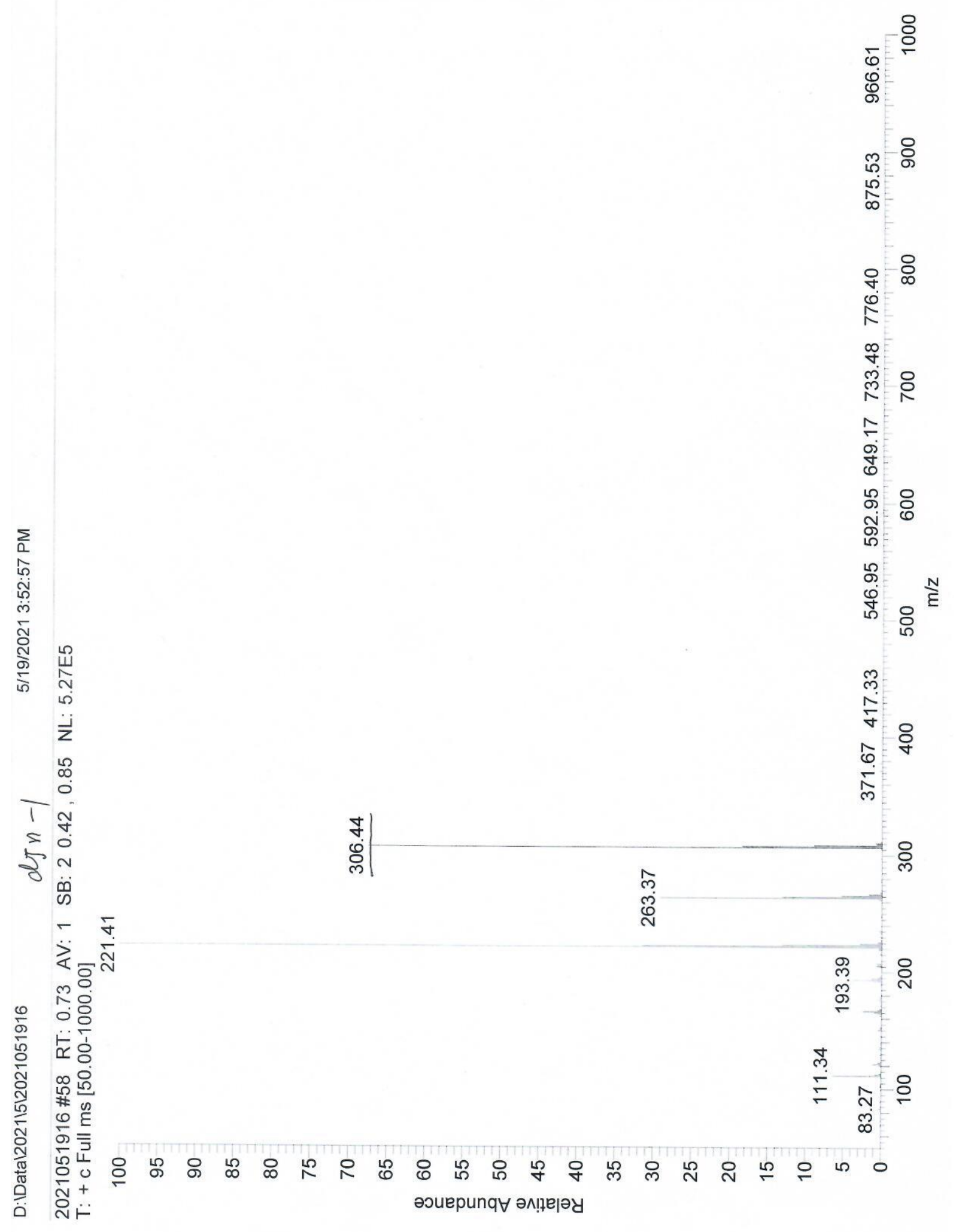

Figure S19. EI-MS spectrum of compound 2. 


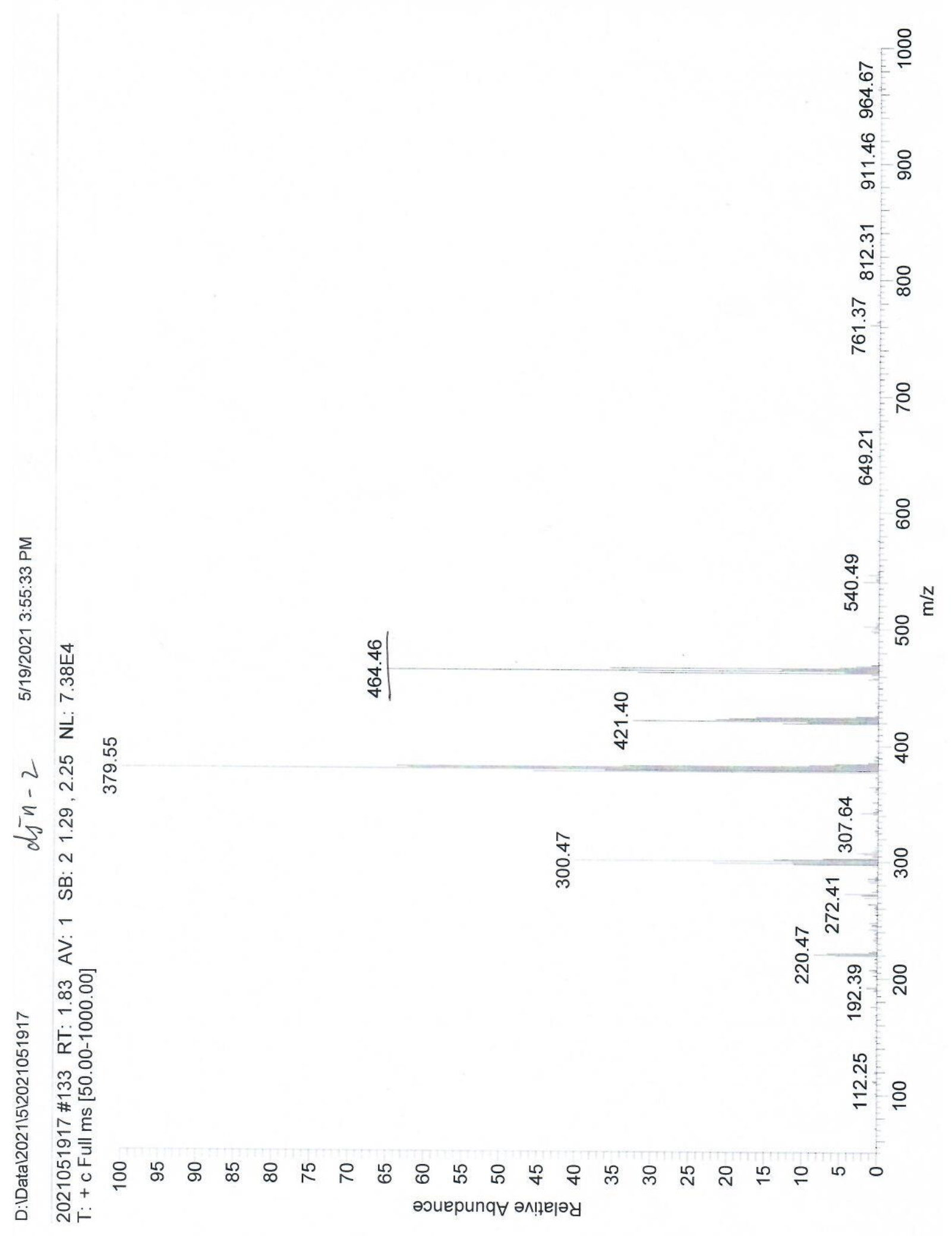

Figure S20. EI-MS spectrum of compound 3. 


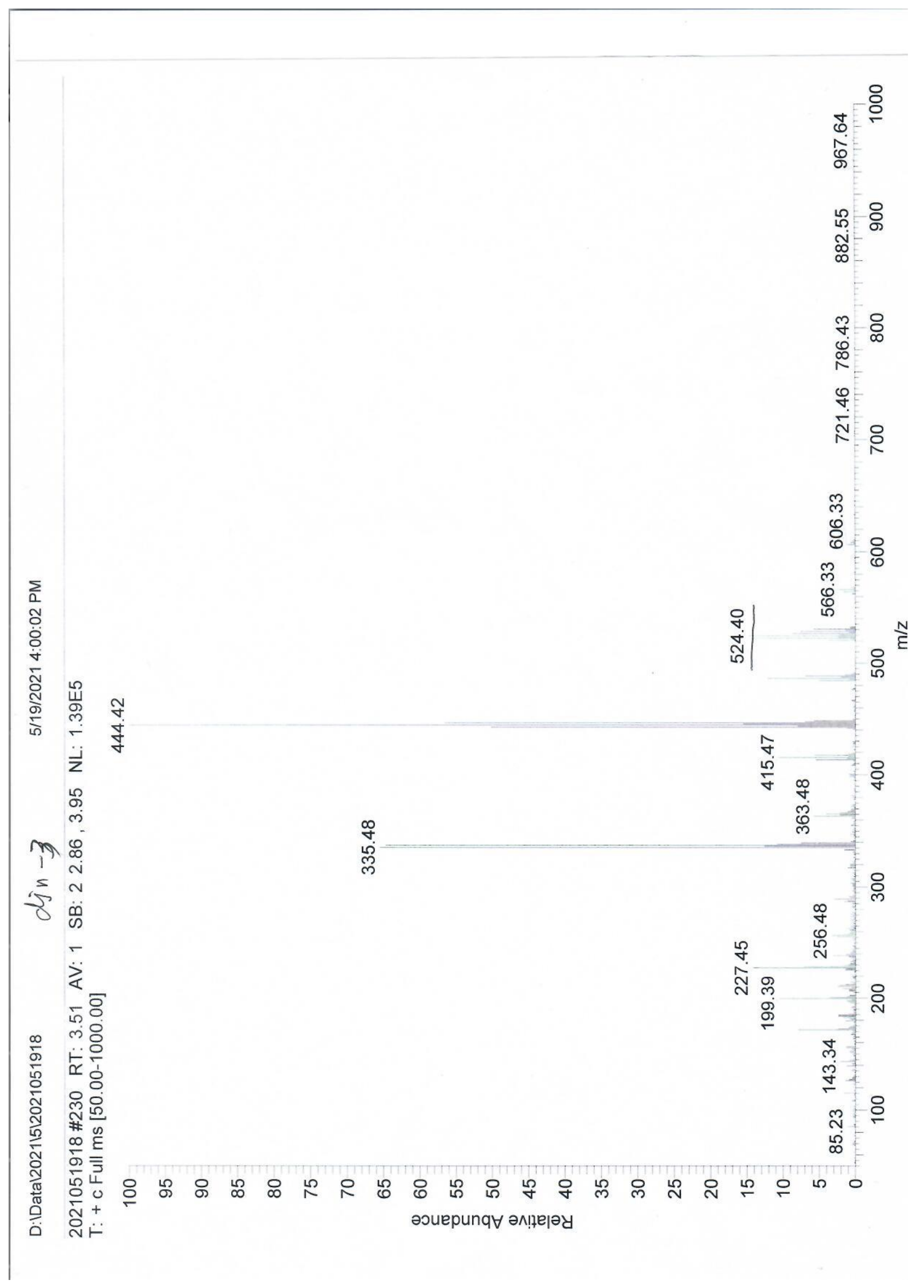

Figure S21. EI-MS spectrum of compound 4. 


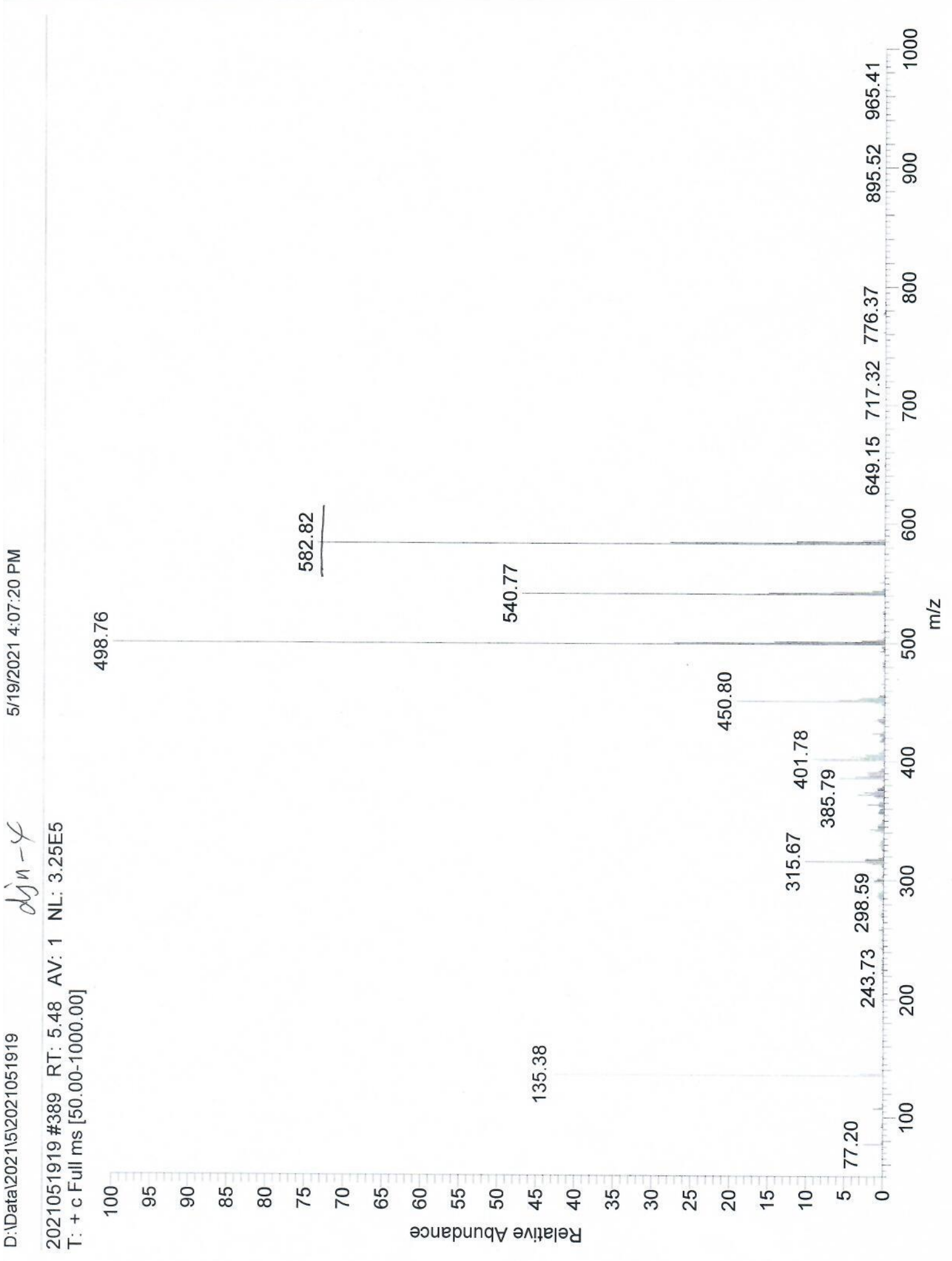

Figure S22. EI-MS spectrum of probe Lipi-BDTO. 